\title{
VARIABILIDADE HORIZONTAL DA FERTILIDADE DO SOLO DE UMA UNIDADE DE AMOSTRAGEM EM SISTE MA PLANTIO DIRETO(1)
}

\author{
V. H. ALVAREZ V.(2) \& A. GUARÇONI M. ${ }^{(3)}$
}

\begin{abstract}
RESUMO
A coleta de amostras de solo com trado é mais simples e rápida do que com a pá de corte, sendo esta, freqüentemente, utilizada no sistema plantio direto para amostragem e determinação da fertilidade média do solo. Com o objetivo de comparar dois sistemas de amostragem localizada do solo (pá de corte ou trado de caneca) quanto à variabilidade horizontal de características químicas, determinar o número de unidades de amostra necessário à formação de uma amostra representativa da unidade de amostragem e demonstrar que a análise da amostra composta apresenta iguais resultados aos obtidos pelas médias aritméticas das análises das amostras simples, realizou-se um estudo em área há 15 anos sob sistema plantio direto. Os sistemas de amostragem localizada foram: pá de corte ( 24 amostras si mples coletadas perpendicularmente ao sulco de plantio e no espaço compreendido entre os pontos médios entre sulcos) e trado (20 amostras simples coletadas no sulco de plantio (Ts), 20 amostras si mples coletadas lateralmente a $10 \mathrm{~cm}$ do sulco (T10) e 20 amostras si mples coletadas a $40 \mathrm{~cm}$ do sulco (T40)). Subamostras representativas das amostras si mples foram misturadas, visando à formação de amostras compostas, tanto para pá de corte quanto para trado. Nas amostras simples e compostas foram determinados os teores de $\mathrm{P}, \mathrm{K}, \mathrm{Ca}^{2+}, \mathrm{Mg}^{2+}$ e $\mathrm{Al}^{3+}$ e os valores de $\mathrm{pH}, \mathrm{H}+\mathrm{Al}$ e P-rem. Foram calculadas as médias das determinações das amostras simples e das compostas, os desvios-padrão e os coeficientes de variação, sendo as médias comparadas pelo teste $t$ de Student. Foi também calculado o número de amostras simples necessário à formação de uma amostra composta, para os dois sistemas de

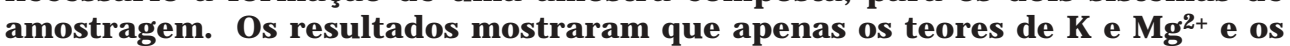
valores de $\mathbf{H}+\mathrm{Al}$ diferiram de um método de amostragem para outro. Na amostragem com trado de caneca, a variabilidade de todas as características avaliadas foi maior do que na amostragem com pá de corte. A variabilidade foi
\end{abstract}

\footnotetext{
(1) Recebido para publicação em agosto de 2002 e aprovado em janeiro de 2003.

(2) Professor do Departamento de Solos da Universidade Federal de Viçosa - UFV. CEP 36571-000 Viçosa (MG). Bolsista do CNPq. E-mail: vhav@ufv.br

(3) Doutorando em Sol os e Nutrição de Plantas do Departamento deSolos, UFV. Bolsista do CNPq. E-mail: agmfertsol o@hotmail.com
} 
baixa para pH, P-rem e H + Al e alta para $\mathrm{P}, \mathrm{Al}^{3+}, \mathrm{Mg}^{2+}, \mathrm{K}$ e $\mathrm{Ca}^{2+}$. Dez amostras simples coletadas com pá de corte ou 27 amostras simples coletadas de forma localizada com trado de caneca (cinco amostras coletadas no sulco de plantio, nove coletadas a $10 \mathrm{~cm}$ do sulco e 13 coletadas no ponto médio entre sulcos) foram necessárias à formação de amostras compostas representativas. As análises das amostras compostas, tanto de pá de corte quanto de trado, apresentaram valores semelhantes às médias das análises das respectivas amostras simples, caracterizando corretamente a fertilidade média da unidade de amostragem.

Termos de indexação: pá de corte, trado, número de amostras si mples, amostra composta.

\section{SUMMARY: HORIZONTAL VARIABILITY OF SOIL FERTILITY IN A SAMPLING UNIT UNDER NO-TILL SYSTEM}

Sampling soil with theauger hole is simpler and faster than with the cutting shovel. The last is frequently used in no till systems to obtain soil samples for fertility analyses. This study had thefol lowing objectives: comparison of two different local ized soil sampling systems concerning thehorizontal variability of chemical soil characteristics; determination of the necessary unit number to compose a representative sample of the area, and the demonstration that mean fertility values obtained from the composite sampleare thesame as theobtained from the arithmetic mean of singlesamplings. Thestudy was carried out in an area under no till system since 15 years. The localized sampl ing systems were: cutting shovel (24 singl e samples collected perpendicularly to the furrow and in the middle of the space betwen two furrows) and auger hole ( 20 single samples collected in the planting furrow (Ts), 20 singlesamples collected $10 \mathrm{~cm}$ besidethefurrow (T10), and 20 singlesamples collected $40 \mathrm{~cm}$ besi de the furrow (T40).Representative sub-samples of both methods were randomly chosen from thesingleones, and mi xed to makeup respectivecompositesamples. $\mathrm{P}, \mathrm{K}, \mathrm{Ca}^{2+}, \mathrm{Mg}^{2+}$, and $\mathrm{Al}^{3+}$, and the values of $\mathrm{pH}, \mathrm{H}+\mathrm{Al}$, and P-rem weredetermined in the singleand compositesamples, and ther means, standard deviation, and variation coefficient calculated. Data means were compared by the Student test. Only $\mathrm{K}, \mathrm{Mg}^{2+}$, and $\mathrm{H}+\mathrm{Al}$ val ues differed according to theempl oyed sampling system. When theauger holewas used, the variability of all studied characteristics and the necessary number of single samples to compose a representative sample were higher than for sampling with the cutting shovel. The variability was low for $\mathrm{pH}, \mathrm{P}-\mathrm{rem}$, and $\mathrm{H}+\mathrm{Al}$, and high for $\mathrm{P}, \mathrm{Al}^{3+}, \mathrm{Mg}^{2+}, \mathrm{K}$, and $\mathrm{Ca}^{2+}$. Ten single samples collected with the cutting shovel or 27 single samples coll lected by the auger hol e(fi vesamples coll lected in thefurrow, ninecol lected $10 \mathrm{~cm}$ besidethefurrow, and 13 collected in the space between two furrows) were necessary to compose representative samples. Analyses of the composite sample for both pieces of equi pment presented values near the medium values obtained with single samples, thus characterizing the medium fertility of sampling units adequately.

Index terms: cutting shovel, auger hole, single samplenumber and composed sample.

\section{INTRODUÇÃO}

A amostragem de sol o éa primeira efundamental etapa de um programa de avaliação da fertilidade do solo, uma vez que as doses de corretivos e de fertilizantes são definidas a partir da interpretação dos resultados de análises químicas realizadas na amostra (Cantarutti et al ., 1999). Portanto, as amostras de sol o devem representar, com exatidão, a área que será corrigida e, ou, adubada, para obter aumento de produtividadee mel hor aproveitamento deinsumos.
$\mathrm{Na}$ amostragem, deve-se considerar a variabilidade dosoloem relaçãoas suas características químicas efísicas, visto que ela influencia o número e a distribuição das amostras simples (unidades de amostra) a serem col etadas por área de manejo de um cultivo, visando à determinação da sua fertilidade média.

Para que a amostra de solo seja representativa, a área amostrada deverá ser subdividida em gl ebas ou tal hões homogêneos, considerando a vegetação, a posi ção topográfica, as características per ceptíveis 
do solo e o histórico da área (Cantarutti et al., 1999). Cada gleba, ou talhão homogêneo a ser amostrado, é considerada como sendouma unidade deamostragem, ou seja, o universo das unidades de amostra.

Em vários estudos, conduzidos de formas distintas, verificou-sea variabilidade decaracterísticas químicas e físicas dos solos sob sistema plantio convencional (aração/gradagem), seja em profundidade (variabilidade vertical), seja em superfície (variabilidade horizontal), nas áreas amostradas (Barreto et al., 1974; Alvarez V. \& Carraro, 1976; Alvarez V. et al., 1986; Santos \& Vasconcel os, 1987; Saraiva et al., 1992; Alves, 1996).

Nosistema plantio direto, porém, as variabilidades, vertical ehorizontal, de características químicas dos sol os tendem a ser mai ores do que no sistema plantio convencional, em virtude da manutenção de linhas de adubação dos plantios anteriores, decorrentes do não-revolvimento do solo (Salet et al., 1996; Anghinoni \& Salet, 1998; Schlindwein et al., 1998). Esta característica émais acentuada para el ementos que apresentam menor mobilidade no solo, como o P e o K (Schlindwein et al., 1998; Schlindwein \& Anghinoni, 2000).

Como no sistema plantio direto, com adubação em linha, a variabilidade horizontal das características químicas dos sol os é mai or do que no sistema plantio convencional, a amostragem tradicionalmente utilizada neste sistema (zig-zag/tradagem) pode não ser a adequada para plantio direto, considerando que o volume e o local de coleta da amostra simples (unidade de amostra) irão influenciar a medida da variabilidade e do valor médio da característica de fertilidade do solo a ser determinada.

Como são poucos os estudos para definir as técnicas de amostragem em áreas manejadas sob sistema plantio direto em Minas Gerais, Cantarutti et al. (1999), considerando vários trabalhos realizados no sul do País, recomendam, para fins de avaliação da fertilidademédia do sol o, a amostragem, em trincheiras, de uma fatia de 3 a $5 \mathrm{~cm}$ de solo, retirada com pá de corte, perpendicularmente aos sulcos e no espaço compreendido entre os pontos médios entre os sulcos, devendo a profundidade de amostragem variar de acordo com o tempo de adoção da prática de plantio direto. Esses autores indicam, ainda, queo número deamostras simples (trincheiras) para formar uma amostra composta deveria variar de 10 a 15 por gl eba (unidade de amostragem).

Na prática, por economia de recursos e detempo, não se analisa a amostra, propriamente dita, da unidade de amostragem, uma vez que não são analizadas, individualmente, as unidades de amostra, fato que permitiria estimar a média e a variância da unidade de amostragem. Rotineiramente, faz-se a análise da amostra composta formada pela mistura de determinado número deamostras simples, quando se quer conhecer a média, e, conscientemente, abstém-se de conhecer a variabilidade.
O objetivo deste estudo foi comparar dois sistemas de amostragem localizada de solo (com pá de corte ou com trado de caneca) e determinar a variabilidade horizontal de características químicas do solo, bem como o número de amostras simples (unidades de amostra) necessárias para formar uma amostra composta (amostra), em área há 15 anos sob sistema plantio direto. Além disso, demonstrar quea fertilidade média obti da pela média aritmética das análises das amostras simples é igual à obtida por meio da análise da amostra composta.

\section{MATERIAL E MÉTODOS}

Para al cançar os objetivos propostos, foi montado um ensaio em área de aproximadamente $1 \mathrm{ha}$, onde vem sendo realizado experimento, comparando diversos tipos de manejo de um ArgissoloVermelho, no município de Coimbra (MG), há 15 anos. No presente estudo, foram utilizadas três parcelas medindo $14 \times 8 \mathrm{~m}$, sob sistema plantio direto. No ensaio, foram utilizados dois sistemas de amostragem local izada de solo em relação ao sulco de plantio, distribuída al eatoriamenteem toda área das parcelas sob plantio direto. A coleta deamostras foi efetuada após a col heita de milho, semeado num espaçamento de $80 \times 20 \mathrm{~cm}$.

A primeira forma de amostragem foi em trincheiras, sendo retirada uma fatia de sol o de $5 \mathrm{~cm}$ de espessura com pá de corte, na camada de $0-10 \mathrm{~cm}$ de profundidade, perpendicularmente aos sulcos e no espaço compreendido entre os pontos médios entre sulcos, de maneira que a linha de adubação estivesse centralizada na faixa de col eta (Figura 1). Foram col etadas 24 amostras simples (unidades de amostra) com pá de corte.

A segunda forma de amostragem foi efetuada com trado de caneca de 5,4 cm de diâmetro, com a retirada das amostras na camada de $0-10 \mathrm{~cm}$ de profundidade. Foram col etadas 60 amostras simples (unidades de amostra) com trado. Esta amostragem, porém, seguiu a seguinte or dem delocalização: 20 amostras coletadas lateralmente a uma distância de $10 \mathrm{~cm}$ do sulco de plantio (T10); 20 amostras coletadas no sul co de plantio (Ts) e 20 amostras col etadas lateral mente a uma distância de $40 \mathrm{~cm}$ do sulco (T40) (Figura 1).

Cada grupo de três amostras simples col etadas com trado (T10, Ts e T40) foi retirado a $90 \mathrm{~cm}$ da trincheira onde uma amostra simples foi coletada com pá de corte (Figura 1).

Foram feitas misturas de subamostras(4) representativas das amostras simples, escol hidas de

\footnotetext{
(4) No texto, subamostra nãoésinônimo de amostra simples, mas, sim, uma fração representativa, seja de amostra simples, seja de amostra composta. A amostra simples, sendo fração da amostra composta, pode ou não representá-la.
} 

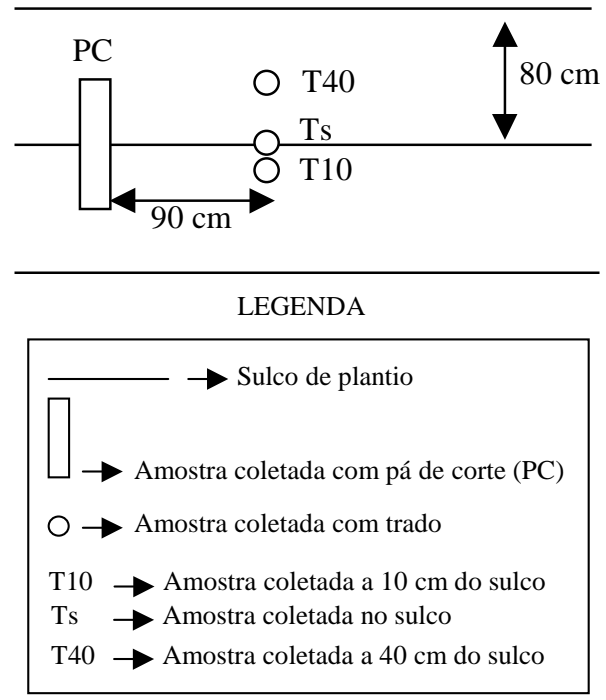

Figura 1. Ti po e localização das coletas de amostras simples de solo.

forma aleatória, após homogeneização das respectivas amostras simples, visando à formação de amostras compostas, tanto de trado quanto de pá de corte. Para trado, as amostras compostas geradas foram: 12 compostas de 5 simples, 6 de 10, 3 de 20, 2 de 30 e 1 amostra composta de 60 amostras simples. O volume de cada subamostra utilizado na mistura foi de: 40, 20, 20, 10 e $10 \mathrm{~cm}^{3}$, para as amostras compostas de 5, 10, 20, 30 e 60 amostras simples, respectivamente. Da mesma forma, foram geradas amostras compostas para pá de corte, sendo: 8 compostas de 3 simples, 3 de 8,2 de 12 e 1 composta de 24 simples. O volume de cada subamostra utilizado na mistura foi de: 100, 50, 50 e $30 \mathrm{~cm}^{3}$ para as amostras compostas de 3, 8, 12 e 24 simples, respectivamente. Em todos os casos, as subamostras a serem misturadas foram previamente pesadas, com base na densidade do solo.

Em todas as amostras si mples e compostas, foram determinados $\mathrm{pH}$ em água (1:2,5), $\mathrm{P}$ eK disponíveis (Mehlich-1), $\mathrm{Al}^{3+}, \mathrm{Ca}^{2+} \mathrm{e} \mathrm{Mg}^{2+}\left(\mathrm{KCl}, 1 \mathrm{~mol} \mathrm{~L}^{-1}\right)$, $\mathrm{H}+\mathrm{Al}\left(\mathrm{Ca}(\mathrm{OAc})_{2}, 0,5 \mathrm{~mol} \mathrm{~L}^{-1} \mathrm{pH} 7\right)$ e P-rem (P em solução após agitação de $60 \mathrm{mg} \mathrm{L}^{-1}$ de $\mathrm{P}$ em $\mathrm{CaCl}_{2}$ 0,01 mol $L^{-1}$, na relação solo:sol ução de 1:10, por 1 h, Alvarez V. et al., 2000).

Como procedimentos estatísticos, foram calculados as médias, os desvios-padrão e os coeficientes de variação de cada grupo de amostras simples: pá de corte (24 amostras), trado (60 amostras), trado $\overline{\mathrm{T}}$ (média aritmética entre os valores obtidos em cada grupo de três amostras simples col etado com trado - T10, Ts e T40) etrado MP (média ponderada entre os valores obtidos em cada grupo de três amostras simples coletado com trado, visando simular a amostragem feita com pá de corte, calculada da seguinte forma: $\mathrm{MP}=(2 \mathrm{~T} 10+\mathrm{Ts}+3 \mathrm{~T} 40) / 6)$; a MP foi cal culada desta forma, porque o vol ume col etado com pá de corte é formado pel o sulco (Ts), por duas regiões a $10 \mathrm{~cm}$ do sulco, direita e esquerda (2T10), e por duas regiões a $40 \mathrm{~cm}$ do sulco, direita e esquerda. Porém, as regiões compreendidas entre 10 e $40 \mathrm{~cm}$ não estavam representadas na amostragem com trado. A forma encontrada para atenuar este fato foi representar a amostra simples retirada a $40 \mathrm{~cm}$ do sulco três vezes (3T 40)). Calcularam-se também as médias, os desvios-padrão e os coeficientes de variação decada grupo de amostras compostas: trado (12 de 5; 6 de 10; 3 de 20; 2 de 30 e 1 de 60) e pá de corte ( 8 de $3 ; 3$ de $8 ; 2$ de 12 e 1 de 24).

As médias das determinações das amostras simples e compostas obtidas com pá de corte e com trado foram comparadas pelo teste te Student. Foram obtidas correlações lineares simples dos val ores das características avaliadas por meio do uso da pá de corte, com os val ores das médias aritmética $(\overline{\mathrm{T}})$ e ponderada (MP) do grupo de três amostras simples coletadas com trado a $90 \mathrm{~cm}$ de distância da trincheira (Figura 1). Foi também determinado o número de amostras simples (unidades de amostra) necessário à formação de uma amostra composta representativa da unidade de amostragem, com definido desvio tolerado, utilizando a pá de corte ou o trado como instrumentos de coleta,

$$
\mathrm{n}=\left(\mathrm{t}_{\alpha / 2} \mathrm{CV} / \mathrm{f}\right)^{2}
$$

em que: $\mathrm{n}$ é o número de amostras simples para formar uma amostra composta representativa de área homogênea, $t_{\alpha / 2}$ é o valor tabelado de distribuição t de Student, o qual depende do nível de probabilidade $\alpha$ edo número degraus deliberdade (n-1), CV éo coeficiente de variação da característica da fertilidade do solo a ser avaliada e f é o desvio admitido em torno da média.

\section{RESULTADOS E DISCUSSÃO}

Os teores de $\mathrm{K}$ e de $\mathrm{Mg}^{2+}$ obtidos com pá de corte foram maiores do que com trado de caneca, considerando os conjuntos de amostras ( $\mathrm{PC}$ e $\mathrm{T}=$ T10 + Ts + T40) (Quadros 1 e 2). Por outro lado, o valor de $\mathrm{H}+\mathrm{Al}$ obtido com trado de caneca foi mai or do que o obtido com pá de corte (Quadros 1 e 2). Como os resultados de $\mathrm{Mg}^{2+}$ e $\mathrm{H}+\mathrm{Al}$ estão relacionados com as aplicações de corretivos da acidez em superfície, as alterações nestas características da fertilidade do solo foram mais facilmente detectadas na amostragem com pá de corte, uma vez que esse tipo de amostragem cobre maior área superficial, em relação à amostragem com trado. Pequenas variações a curtas distâncias, causadas pela aplicação de corretivos a lanço, são menos expressivas, considerando o el evado volume desol oamostrado, tanto queas variabilidades de $\mathrm{Mg}^{2+}$ e H + Al foram menores na amostragem com pá de corte do que na amostragem com trado (Quadro 1). 
Quadro 1. Valores médios e coeficientes de variação de características da fertilidade do solo, por dois sistemas de amostragem, em área há 15 anos sob sistema plantio direto

\begin{tabular}{|c|c|c|c|c|c|c|c|}
\hline \multirow{2}{*}{ Característica } & \multicolumn{7}{|c|}{ Forma de amostragem } \\
\hline & $P C(1)$ & $\mathrm{T} 10^{(2)}$ & $\mathbf{T s}^{(3)}$ & $\mathrm{T40}(4)$ & $\mathbf{T}(5)$ & $\bar{T}(6)$ & $\mathbf{M P}(7)$ \\
\hline $\mathrm{pH}$ & 5,1 & 5,1 & 5,4 & 5,1 & 5,2 & 5,2 & 5,1 \\
\hline C.V. (\%) & 4,31 & 4,31 & 5,74 & 4,31 & 5,58 & 4,09 & 3,92 \\
\hline $\mathrm{K}, \mathrm{mg} \mathrm{dm}-3$ & 123,0 & 81,0 & 135,0 & 79,0 & 98,0 & 98,0 & 89,0 \\
\hline C.V. (\%) & 24,76 & 28,72 & 25,69 & 40,57 & 40,39 & 24,87 & 27,92 \\
\hline $\mathrm{Al}^{3+}, \mathrm{cmol}_{\mathrm{c}} \mathrm{dm}^{-3}$ & 0,29 & 0,29 & 0,28 & 0,25 & 0,27 & 0,27 & 0,27 \\
\hline C.V. (\%) & 41,37 & 55,17 & 60,71 & 56,00 & 55,56 & 45,82 & 44,44 \\
\hline $\mathrm{Ca}^{2+}, \mathrm{cmol}_{\mathrm{c}} \mathrm{dm}^{-3}$ & 2,14 & 2,10 & 3,35 & 2,09 & 2,51 & 2,51 & 2,30 \\
\hline C.V. (\%) & 26,64 & 24,76 & 32,24 & 25,36 & 37,85 & 24,90 & 23,91 \\
\hline $\mathrm{Mg}^{2+}, \mathrm{cmol}_{\mathrm{c}} \mathrm{dm}^{-3}$ & 0,62 & 0,37 & 0,32 & 0,39 & 0,36 & 0,36 & 0,37 \\
\hline C.V. (\%) & 27,42 & 37,84 & 40,63 & 41,03 & 41,67 & 37,57 & 37,84 \\
\hline $\mathrm{H}+\mathrm{Al}, \mathrm{cmol}_{\mathrm{c}} \mathrm{dm}^{-3}$ & 5,61 & 5,96 & 6,14 & 5,79 & 5,96 & 5,96 & 5,90 \\
\hline C.V. (\%) & 7,49 & 10,74 & 10,91 & 9,84 & 10,57 & 8,91 & 8,81 \\
\hline P-rem, mg L-1 & 34,4 & 32,7 & 34,4 & 32,3 & 33,1 & 33,1 & 32,77 \\
\hline C.V. (\%) & 10,93 & 7,55 & 13,11 & 8,76 & 10,45 & 8,41 & 7,84 \\
\hline
\end{tabular}

(1) Média e CV das 24 amostras coletadas com pá de corte. ${ }^{(2)}$ Amostras col etadas com trado de caneca a $10 \mathrm{~cm}$ do sulco de plantio. (3) Amostras coletadas com trado no sulco de plantio. ${ }^{(4)}$ Amostras coletadas com trado a $40 \mathrm{~cm}$ do sulco de plantio. ${ }^{(5)} 60$ amostras coletadas com trado. ${ }^{(6)}$ Médias aritméticas dos três locais de amostragem com trado. ${ }^{(7)}$ Médias ponderadas dos três locais de amostragem com trado: $\mathrm{MP}=(2 \mathrm{~T} 10+\mathrm{Ts}+3 \mathrm{~T} 40) / 6$

Quadro 2. Valores do teste t de Student para as comparações de valores médios de características da fertilidade do solo, por dois métodos de amostragem, em área há 15 anos sob sistema plantio direto

\begin{tabular}{|c|c|c|c|c|c|c|c|c|}
\hline Comparação & pH & $\mathbf{P}$ & $\mathbf{K}$ & $\mathbf{A l}^{3+}$ & $\mathrm{Ca}^{2+}$ & $\mathbf{M g}^{2+}$ & $\mathbf{H}+\mathbf{A l}$ & P-rem \\
\hline & \multicolumn{8}{|c|}{$-\mathrm{t}$} \\
\hline $\begin{array}{l}P C^{(1)} \text { Vs } T^{(2)} \\
P C \text { vs } M P^{(3)}\end{array}$ & $\begin{array}{l}1,505 \\
0,000\end{array}$ & $\begin{array}{r}1,073 \\
-0,196\end{array}$ & $\begin{array}{l}-2,749^{* *} \\
-3,912^{* *}\end{array}$ & $\begin{array}{l}-0,576 \\
-0,538\end{array}$ & $\begin{array}{l}1,763 \\
0,920\end{array}$ & $\begin{array}{l}-6,819^{* *} \\
-5,136^{* *}\end{array}$ & $\begin{array}{l}2,478^{*} \\
1,999^{*}\end{array}$ & $\begin{array}{l}-1,499 \\
-1,597\end{array}$ \\
\hline Ts(4) vs T 10 & $3,440^{* *}$ & $4,673^{* *}$ & $5,637^{* *}$ & $-0,187$ & $4,546 * *$ & $-1,141$ & 0,847 & 1,441 \\
\hline Ts vs T40 & $3,440^{* *}$ & $5,322^{* *}$ & $5,169^{* *}$ & 0,594 & $4,565^{* *}$ & $-1,480$ & 1,734 & 1,719 \\
\hline T10 vs T 40 & 0,000 & 0,991 & 0,220 & 0,820 & 0,059 & $-0,410$ & 0,865 & 0,464 \\
\hline PC vs PC (1 de 24$)^{(5)}$ & 0,000 & 0,152 & 0,220 & $-0,879$ & $-0,168$ & $-0,056$ & 0,000 & $-0,485$ \\
\hline$P C$ vs PC ( 2 de 12$)$ & 0,000 & 0,143 & 0,134 & $-0,670$ & 0,000 & 0,080 & $-0,543$ & 0,036 \\
\hline PC vs PC (3 de 8$)$ & $-0,748$ & $-0,104$ & 0,328 & 0,254 & 0,057 & $-0,285$ & 1,262 & $-0,088$ \\
\hline PC vs PC (8 de 3$)$ & $-1,102$ & 0,051 & 0,000 & 0,628 & $-0,089$ & 0,000 & 0,416 & 0,072 \\
\hline T vs T (1 de 60$)^{(6)}$ & 0,339 & 0,013 & $-0,199$ & $-0,197$ & 0,321 & $-0,852$ & 0,546 & 0,426 \\
\hline T vs T ( 2 de 30$)$ & 0,000 & 0,027 & $-0,210$ & 0,185 & 0,393 & $-1,113$ & 0,397 & 0,841 \\
\hline T vs T (3 de 20 ) & 0,000 & 0,135 & $-0,430$ & 0,000 & 0,071 & $-1,701$ & 0,648 & 0,836 \\
\hline $\mathrm{T}$ vs $\mathrm{T}$ (6 de 10$)$ & $-0,827$ & $-0,036$ & $-1,120$ & 0,801 & $-0,278$ & $-2,879^{* *}$ & 0,682 & 1,321 \\
\hline $\mathrm{T}$ vs $\mathrm{T}$ (12 de 5$)$ & $-1,130$ & $-0,132$ & $-0,505$ & 0,676 & $-0,138$ & $-3,765^{* *}$ & 1,269 & 1,083 \\
\hline
\end{tabular}

(1) Média de 24 amostras col etadas com pá de corte. ${ }^{(2)}$ Média de 60 amostras col etadas com trado. ${ }^{(3)}$ Média ponderada dos três locais de amostragem com trado ((2T10 + Ts +3T40)/6). (4) Média das amostras por local de amostragem com trado - Ts (amostra col etada no sulco de plantio), T10 (amostra coletada a $10 \mathrm{~cm}$ do sulco de plantio) e T40 (amostra coletada a $40 \mathrm{~cm}$ do sulco de plantio). ${ }^{(5)}$ Média das amostras compostas formadas por amostras simples coletadas com pá de corte. (6) Média das amostras compostas formadas por amostras simples coletadas com trado. *, **: Significativos a 5 e $1 \%$. 
Os maiores teores de $\mathrm{K}$ obtidos na amostragem com pá de corte, em relação à amostragem com trado, considerando o grupo de amostras (T10, Ts e T40), podem ser explicados pela aplicação do nutriente no sulco de plantio e pela lavagem da parte aérea das plantas de milho, que, segundo Salet et al. (1996) e Anghinoni \& Salet (1998), tendem a concentrar o K próximo ao sulco de plantio. Mesmo não ocorrendo diferença nos teores de $\mathrm{K}$ entre a amostragem a $10 \mathrm{~cm}$ e a $40 \mathrm{~cm}$ do sulco, realizada com trado (Quadros 1 e 2), e considerando os el evados teores obtidos em Ts (Quadro 1), provenientes apenas da aplicação localizada de K no sulco de plantio, podese aceitar a hipótese dos autores supracitados, por não ter sido a amostragem com trado capaz de detectar a área de abrangência desta concentração. $\mathrm{Na}$ amostragem com pá de corte, também não foi detectada a área de maior concentração de K, mas esta estaria embutida no elevado volume de solo amostrado, gerando maiores teores de $\mathrm{K}$ na amostragem com pá de corte.
As demais características da fertilidade do solo não apresentaram diferença pelo teste t a 5 e $1 \%$, quando foram utilizadas a pá de corte ou o trado de caneca para coleta de unidades de amostra (Quadros 1, 2 e 3). No entanto, o teor médio de $\mathrm{P}$ disponível obtido nas 60 amostras coletadas com trado de caneca foi $20,5 \%$ mai or do que o obtido, em média, com pá de corte (Quadro 3). Essa diferença pode ser atribuída não só aos teores de P disponível no sul co de plantio, queforam, em média, $164 \%$ mais elevados do que os encontrados externamente ao sulco (Quadro 3), mas também à maior diluição da concentração deP presente no sul co na amostragem com pá decorte, já quea proporção de solo amostrado entrelinha : sulco é de 5,33:1 neste tipo de amostragem e de 2:1 na amostragem com trado de caneca.

Esteresultado difere completamente do obtido por Schlindwein \& Anghinoni (1998), que encontraram maiores teores de $\mathrm{P}$ disponível utilizando a pá de corte. Esses autores utilizaram a pá de corte e o

Quadro 3. Teores, médias e coeficiente de variação (C.V.) de fósforo disponível, por dois sistemas de amostragem, em área há 15 anos sob sistema plantio direto

\begin{tabular}{|c|c|c|c|c|c|c|c|}
\hline \multirow{2}{*}{ Amostra } & \multicolumn{7}{|c|}{ Forma de amostragem } \\
\hline & $P C(1)$ & T10(2) & $\mathbf{T s}^{(3)}$ & T40(4) & $\mathbf{T}^{(5)}$ & $\bar{T}(\mathbf{6})$ & $M P(7)$ \\
\hline & & & & & & & \\
\hline 1 & 72,1 & 31,6 & 194,3 & 75,5 & & 100,5 & 80,7 \\
\hline 2 & 67,3 & 63,9 & 303,2 & 39,3 & & 135,5 & 91,5 \\
\hline 3 & 84,5 & 91,3 & 132,9 & 52,7 & & 92,3 & 78,9 \\
\hline 4 & 76,9 & 36,5 & 109,1 & 40,4 & & 62,0 & 50,6 \\
\hline 5 & 98,4 & 31,1 & 119,7 & 51,9 & & 67,6 & 56,3 \\
\hline 6 & 68,1 & 45,0 & 121,0 & 61,2 & & 75,7 & 65,8 \\
\hline 7 & 72,9 & 94,5 & 46,3 & 64,8 & & 68,5 & 71,6 \\
\hline 8 & 110,4 & 125,2 & 123,2 & 66,8 & & 105,1 & 95,7 \\
\hline 9 & 83,3 & 75,7 & 245,0 & 54,9 & & 125,2 & 93,5 \\
\hline 10 & 46,6 & 30,6 & 119,0 & 21,3 & & 57,0 & 40,7 \\
\hline 11 & 52,6 & 83,2 & 87,2 & 41,6 & & 70,7 & 63,1 \\
\hline 12 & 55,0 & 65,3 & 70,2 & 23,1 & & 52,9 & 45,0 \\
\hline 13 & 37,4 & 19,4 & 218,7 & 28,8 & & 89,0 & 57,3 \\
\hline 14 & 63,0 & 51,7 & 29,2 & 51,8 & & 44,2 & 48,0 \\
\hline 15 & 41,8 & 49,7 & 47,4 & 21,8 & & 39,6 & 35,4 \\
\hline 16 & 66,1 & 62,3 & 205,7 & 61,2 & & 109,7 & 85,7 \\
\hline 17 & 56,2 & 21,1 & 130,3 & 64,1 & & 71,8 & 60,8 \\
\hline 18 & 42,2 & 43,9 & 203,5 & 29,0 & & 92,1 & 63,1 \\
\hline 19 & 114,8 & 69,9 & 114,7 & 81,1 & & 88,6 & 83,0 \\
\hline 20 & 73,7 & 27,2 & 134,4 & 36,6 & & 66,0 & 49,8 \\
\hline 21 & 44,6 & & & & & & \\
\hline 22 & 70,9 & & & & & & \\
\hline 23 & 46,2 & & & & & & \\
\hline 24 & 63,8 & & & & & & \\
\hline $\bar{Y}$ & 67,0 & 56,0 & 137,8 & 48,4 & 80,7 & 80,7 & 65,8 \\
\hline C.V. (\%) & 30,97 & 50,19 & 51,50 & 37,46 & 74,81 & 31,98 & 27,96 \\
\hline
\end{tabular}

(1) Amostras col etadas com pá de corte. ${ }^{(2)}$ Amostras col etadas com trado de caneca a $10 \mathrm{~cm}$ do sulco de plantio. ${ }^{(3)}$ Amostras col etadas com trado no sulco de plantio. ${ }^{(4)}$ Amostras coletadas com trado a $40 \mathrm{~cm}$ do sulco de plantio. ${ }^{(5)} 60$ amostras coletadas com trado, teores presentes nas colunas T10, Ts e T40. ${ }^{(6)}$ Média aritmética dos três locais de amostragem com trado ((T10 + Ts + T40)/3). (7) Média ponderada dos três locais de amostragem com trado ((2T10 + Ts + 3T40)/6). 
trado de rosca para coleta de amostras em área há 12 anos sob plantio direto e atribuíram o resultado às perdas de solo da camada superficial, onde estariam concentrados os nutrientes no momento da amostragem com trado de rosca. Por outro lado, vale destacar que a amostragem com trado de rosca não foi feita, pelos autores, no sulco de plantio, mas, sim, próxima a este, explicando, possivelmente, a diferença de resultados entre os trabalhos.

A manutenção de linhas de adubação no sistema plantio direto, dependendo da forma de amostragem, pode alterar a medida das características da fertilidade do solo, especialmente para K (Quadros 1 e2) e, como observado por Schlindwein \& Anghinoni (1998), para P disponível (Quadro 3). Entretanto, tal fato nem semprese reverteem mudança da classe de fertilidade. Quando se utiliza modelagem no cálculo para obtenção das doses recomendáveis a partir dos val ores de características da fertilidade do solo, podem ocorrer discrepâncias na recomendação de acordo com o método de amostragem utilizado. Dessa forma, a dose mais exata seria cal culada pel o método de amostragem no qual os valores das características da fertilidade mais se aproximassem dos reais teores médios do solo.

Ao calcular a média ponderada (MP) dos três locais de amostragem com trado ((2T10 +Ts +3T 40)/6), os valores obtidos foram muito semelhantes aos obtidos quando se utilizou a pá de corte, para a maioria das características da fertilidade do solo estudadas (Quadros 1, 2 e 3), especialmente para P disponível. Desta forma, pode-se inferir que a amostra simples (unidade deamostra) col etada com pá de corte nada mais é do que uma amostra composta (amostra) formada por diversas amostras simples (unidades de amostra) col etadas, de forma localizada, com trado de caneca. Exceção feita às características $\mathrm{Mg}^{2+}, \mathrm{H}+\mathrm{Al}$ e $\mathrm{K}$, pois, como já explicado, na amostragem com pá de corte cobre-se maior área superficial em relação à amostragem com trado de caneca, e, mesmo fazendo-se a MP dos três locais de amostragem com trado, não se obtêm val ores semel hantes aos da amostragem com pá de corte, para características que sofrem influência da aplicação de corretivo a lanço $\left(\mathrm{Mg}^{2+} \mathrm{e} \mathrm{H}+\mathrm{Al}\right)$.

No caso do $K$, a ponderação, que simula a amostragem com pá de corte, deveria atribuir maior peso aos teores encontrados no sulco de plantio, uma vez que estes foram, em média, $69 \%$ mais el evados do que os encontrados externamente ao sulco (Quadro 1), sendo esta diferença muito menor do que a observada para o P disponível (164\%). Portanto, a MP dos três locais de amostragem com trado ((2T10 +Ts +3T 40)/6) aval ia mais adequadamente os teores de $\mathrm{P}$ disponível em relaçãoà amostragem com pá de corte do que os teores de $\mathrm{K}$.

A variabilidade de todas as características da fertilidadedo solo estudadas foi maior na amostragem com trado (60 amostras) do que na amostragem com pá de corte (Quadros 1 e 3), como observado por Schlindwein \& Anghinoni (1998), exceção feita a Prem (Quadro 1).

A variabilidade obtida na amostragem com pá de corte apresentou, no entanto, pouca diferença da variabilidade obtida quando se utilizaram a média aritmética $(\bar{T})$ e a média ponderada (MP) dos três locais de amostragem com trado, para todas as características da fertilidade do solo, exceção feita ao $\mathrm{Mg}^{2+}$ e ao $\mathrm{Al}^{3+}$ (Quadros 1 e 3). Esse resultado evidencia que a unidade de amostra col etada com pá de corte nada mais édo que uma amostra formada por diversas unidades de amostra coletadas com trado de caneca. Se isto ocorre, e as unidades de amostra são col etadas com trado em locais que apresentem diferentes teores, especialmente dos nutrientes aplicados em linha, é evidente a menor variabilidade obtida com pá de corte, em relação à variabilidade obtida com trado (60 amostras) (Quadros 1 e 3).

Provavelmente, pela mesma razão, Schlindwein et al. (1998), que avaliaram diversos volumes de amostras simples em área sob plantio direto, concluíram que amostras de menor volume tendem a apresentar maior variabilidade de $\mathrm{P}$ e $\mathrm{K}$ disponíveis, quando comparadas a amostras de mai or volume. Caso específico de amostras simples (unidades de amostra) coletadas com trado $\left(0,23 \mathrm{dm}^{3}\right)$ e com pá de corte $\left(4,5 \mathrm{dm}^{3}\right)$.

A ordem decrescente de variabilidade, quando utilizada a pá de corte, foi: $\mathrm{Al}^{3+}>\mathrm{P}>\mathrm{Mg}^{2+}>\mathrm{Ca}^{2+}>\mathrm{K}$ $>$ P-rem $>\mathrm{H}+\mathrm{Al}>\mathrm{pH}\left(\mathrm{H}_{2} \mathrm{O}\right.$ ) (Quadros 1e3). Quando se utilizou o trado de caneca como instrumento de coleta (60 amostras), a ordem decrescente de variabilidadefoi: $\mathrm{P}>\mathrm{Al}^{3+}>\mathrm{Mg}^{2+}>\mathrm{K}>\mathrm{Ca}^{2+}>\mathrm{H}+\mathrm{Al}$ $>$ P-rem $>$ pH $\left(\mathrm{H}_{2} \mathrm{O}\right.$ ) (Quadros 1 e 3 ). Nos dois casos, as elevadas variabilidades de $\mathrm{Al}^{3+}$ ede $\mathrm{Mg}^{2+}$, indicadas pelo CV, dependem mais do pequeno val or da média obtido para estas características do que da real variabilidade presente no solo. Como o CV é calculado pela razão do desvio-padrão pela média, quanto menor for ovalor desta, em relação ao mesmo desvio-padrão, maior será o CV. Por isso, pode-se sugerir que as variabilidades de quaisquer características estudadas devam ser comparadas pel o desvio-padrão (s) em conjunto com o CV, o qual sofre grande influência da média.

O valor do CV obtido para P disponível, ao utilizar o trado de caneca na coleta de amostras (60 unidades de amostra) (Quadro 3), apresentou magnitude semel hante ao obtido por Barreto et al. (1974), num Argissolo Vermel ho-Amarel o câmbico fase terraço, sem cultivo, em amostras simples coletadas com trado a $0-10 \mathrm{~cm}$ de profundidade, e ao obtido por Alvarez V. \& Carraro (1976), num Latossolo Vermel ho, sem cultivo, em amostras de $0-20 \mathrm{~cm}$ de profundidade, distanciadas de 14,7 em 14,7 m, coletadas com trado. I sto significa que o instrumento de coleta utilizado nos trabal hos supracitados (trado) 
tevegrandesensibilidadena mediçãoda variabilidade a curta distância de P disponível, pois, em ambos os casos, a amostragem foi feita em áreas sem cultivo.

No entanto, é obvio queáreas onde a adubação foi realizada em linha apresentem maior variabilidade de $\mathrm{P}$ disponível do que áreas sem cultivo. Assim, pode-se presumir que a medida da variabilidade (CV), obtida por determinado método, nem sempre correspondeà real variabilidade $\left(s^{2}\right)$ presenteno solo, e que, muitas vezes, os programas de adubação são montados sobre bases pouco confiáveis.

Da mesma forma, ao utilizar a pá de corte na coleta de amostras, os valores dos CV obtidos para P e K disponíveis (Quadros 1 e 3) apresentaram magnitudes semel hantes aos valores obtidos por Salet et al. (1996), Schlindwein et al. (1998), Schlindwein \& Anghinoni (1998) e Schlindwein \& Anghinoni (2000), em diferentes lavouras no sistema plantio direto.

Consi derando quea área amostrada neste estudo está há 15 anos sob sistema plantio direto, a semelhança entre as variabilidades obtidas nos diferentes trabalhos não corrobora, em parte, a hipótese de menor variabilidade horizontal no decorrer dotempo, pela não-coincidência das linhas deadubação, sugerida por Anghinoni \& Salet (1998), posto que são comparadas lavouras com diferentes tempos de implantação do sistema plantio direto.

Por outro lado, a col eta de amostras com pá de corte, recomendada para o sistema plantio direto, tendea detectar as variabilidades obtidas na mai oria dos trabalhos num mesmo nível, pois dilui o efeito das aplicações local izadas dado o el evado vol ume de solo amostrado, demonstrando que esta técnica (trincheira) pode não ser adequada a essa comparação. Tanto que Schlindwein \& Anghinoni (2000), coletando amostras com pá de corte, em lavouras de três a 12 anos sob plantio direto e adubadas em linha, não observaram relação entre as variabilidades das características avaliadas ( $\mathrm{P}$ e K) e o tempo de cultivo.

Correlações lineares simples dos valores das características da fertilidade do solo obtidos nas amostras coletadas com pá de corte (PC) com os valores das médias, aritmética $(\bar{T})$ e ponderada (MP), do grupo correspondente de três amostras simples coletadas com trado, foram significativas, exceto para P disponível, considerando PC ea média aritmética $(\bar{T})$ (Quadro 4), apresentando, porém, pequenas magnitudes para $\mathrm{P}(\mathrm{PC}-\mathrm{MP}), \mathrm{K}, \mathrm{Al}^{3+}, \mathrm{Ca}^{2+}$, $\mathrm{H}+\mathrm{Al}$ e P-rem (Quadro 4).

Considerando que o grupo de amostras col etado com trado (T10, Ts e T40) foi retirado a $90 \mathrm{~cm}$ da amostra correspondente coletada com pá de corte (Figura 1), pode-se inferir que a variabilidade das características da fertilidade, especialmente o P disponível, seja influenciada por diferenças de composição a curtas distâncias no solo, como sugerido por van den Hende \& Cottenie (1960), J ackson (1970) e Saraiva et al. (1992).

As amostras compostas, formadas a partir de subamostras retiradas das amostras simples (unidades de amostra) coletadas com pá de corte, apresentaram, em média, valores das características da fertilidade do solo semel hantes às médias de todas as unidades de amostra coletadas com pá de corte (Quadros 1, 2, 3 e 5). O mesmo ocorreu nas amostras compostas formadas a partir de subamostras retiradas das amostras simples col etadas com trado de caneca, exceto para $\mathrm{Mg}^{2+}$ nas amostras compostas formadas por menor número de amostras simples (6 amostras compostas de 10 amostras simples e 12 amostras compostas de 5 amostras simples) (Quadros 1, 2, 3 e 5).

Este fato demonstra que, para determinada área (talhão), o valor médio de cada característica da fertilidade do solo pode ser obtido pela média das análises das amostras simples (o que encarece o custo do programa de avaliação da fertilidade) ou por análises das amostras compostas formadas a partir das amostras simples, como observado por Santos \& Vasconcellos (1987). Neste caso, alguns cuidados devem ser tomados para que as amostras compostas representem fielmente a fertilidade média da área amostrada: o volume de sol o retirado para formar cada amostra simples deveser o mesmo, a homogeneização do conjunto das amostras simples

Quadro 4. Coeficiente de correlação linear simples dos valores das características da fertilidade do solo das amostras coletadas com pá de corte (PC) com as médias aritméticas $(\bar{T})$ e ponderadas (MP) do grupo correspondente de três amostras simples coletado com trado a $90 \mathrm{~cm}$

\begin{tabular}{ccccccccc}
\hline \multirow{2}{*}{ Correlação } & \multicolumn{9}{c}{ Característica da fertilidade do solo } & \multirow{2}{*}{ P-rem } \\
\cline { 2 - 7 } & $\mathbf{p H}$ & $\mathbf{P}$ & $\mathbf{K}$ & $\mathbf{A l} \mathbf{3}^{3+}$ & $\mathbf{C a}^{2+}$ & $\mathbf{M g}^{2+}$ & $\mathbf{H}+\mathbf{A l}$ & \\
\hline PC- $\bar{T}$ & $0,726^{* *}$ & 0,321 & $0,558^{*}$ & $0,607^{* *}$ & $0,690^{* *}$ & $0,852^{* *}$ & $0,696^{* *}$ & $0,517^{*}$ \\
PC-MP & $0,736^{* *}$ & $0,576^{* *}$ & $0,547^{*}$ & $0,631^{* *}$ & $0,750^{* *}$ & $0,853^{* *}$ & $0,728^{* *}$ & $0,597^{* *}$ \\
\hline
\end{tabular}

o, $\mathrm{e}^{* *}$ : Significativos a 10,5 e $1 \%$, respectivamente. 
Quadro 5. Valores médios e coeficientes de variação (C.V.) de características da fertilidade do solo em amostras compostas, por dois sistemas de amostragem, em área há 15 anos sob sistema plantio direto

\begin{tabular}{|c|c|c|c|c|c|c|c|c|c|}
\hline \multirow{2}{*}{ Correlação } & \multicolumn{4}{|c|}{ Pá de corte } & \multicolumn{5}{|c|}{ Trado } \\
\hline & $8 \mathrm{de} 3^{(1)}$ & 3 de 8 & 2 de 12 & 1 de 24 & 12 de $5^{(2)}$ & 6 de 10 & 3 de 20 & 2 de 30 & 1 de 60 \\
\hline $\mathrm{pH}$ & 5,2 & 5,2 & 5,1 & 5,1 & 5,3 & 5,3 & 5,2 & 5,2 & 5,1 \\
\hline C.V. (\%) & 3,8 & 1,9 & 2,0 & 0,0 & 3,7 & 2,0 & 3,8 & 3,8 & 0,0 \\
\hline$P, \mathrm{mg} \mathrm{dm}^{-3}$ & 66,6 & 68,3 & 64,8 & 63,7 & 83,1 & 81,6 & 75,9 & 79,5 & 79,9 \\
\hline C.V. (\%) & 15,5 & 7,6 & 14,4 & 0,0 & 36,5 & 16,4 & 18,2 & 45,0 & 0,0 \\
\hline $\mathrm{K}, \mathrm{mg} \mathrm{dm}^{-3}$ & 123,0 & 117,0 & 120,0 & 116,0 & 104,0 & 108,0 & 108,0 & 104,0 & 106,0 \\
\hline C.V. (\%) & 14,8 & 2,0 & 2,3 & 0,0 & 19,6 & 17,1 & 7,4 & 13,6 & 0,0 \\
\hline $\mathrm{Al}^{3+}, \mathrm{cmol}_{\mathrm{c}} \mathrm{dm}^{-3}$ & 0,26 & 0,27 & 0,35 & 0,40 & 0,24 & 0,22 & 0,27 & 0,25 & 0,30 \\
\hline C.V. (\%) & 34,6 & 55,6 & 20,0 & 0,0 & 20,8 & 18,2 & 22,2 & 28,0 & 0,0 \\
\hline $\mathrm{Ca}^{2+}, \mathrm{cmol}_{\mathrm{c}} \mathrm{dm}^{-3}$ & 2,16 & 2,12 & 2,14 & 2,24 & 2,55 & 2,62 & 2,47 & 2,24 & 2,20 \\
\hline C.V. (\%) & 18,5 & 14,2 & 5,1 & 0,0 & 24,7 & 10,7 & 19,0 & 25,4 & 0,0 \\
\hline $\mathrm{Mg}^{2+}, \mathrm{cmol}_{\mathrm{c}} \mathrm{dm}^{-3}$ & 0,62 & 0,65 & 0,61 & 0,63 & 0,53 & 0,54 & 0,51 & 0,48 & 0,49 \\
\hline C.V. (\%) & 14,5 & 18,5 & 6,6 & 0,0 & 15,1 & 9,3 & 7,8 & 0,0 & 0,0 \\
\hline $\mathrm{H}+\mathrm{Al}, \mathrm{cmol}_{\mathrm{c}} \mathrm{dm}^{-3}$ & 5,53 & 5,28 & 5,78 & 5,61 & 5,72 & 5,78 & 5,72 & 5,78 & 5,61 \\
\hline C.V. (\%) & 9,9 & 6,3 & 4,0 & 0,0 & 5,6 & 4,8 & 3,3 & 4,0 & 0,0 \\
\hline P-rem, mg L-1 & 34,30 & 34,60 & 34,30 & 36,30 & 31,98 & 31,20 & 31,40 & 31,00 & 31,60 \\
\hline C.V. (\%) & 3,7 & 4,5 & 6,0 & 0,0 & 5,0 & 2,6 & 3,1 & 5,3 & 0,0 \\
\hline
\end{tabular}

(1) $\mathrm{r}$ amostras compostas formadas por $\mathrm{n}$ amostras simples col etadas com pá de corte, no caso oito amostras compostas formadas por três amostras simples. ${ }^{(2)} \mathrm{r}$ amostras compostas formadas por $\mathrm{n}$ amostras simples col etadas com trado, no caso 12 amostras compostas formadas por cinco amostras simples.

deve ser muito bem feita e, principalmente, o local de coleta da amostra simples deve ser considerado, caso a amostragem seja feita com trado em áreas que receberam adubação em linha.

Nos quadros 6 e 7, pode-se observar a influência do local de coleta das amostras simples com trado no teor médio de $\mathrm{P}$ disponível em cada amostra composta. A escol ha das amostras simples, que compuseram cada amostra composta (no estudo, foram utilizadas subamostras para formação de diferentes amostras compostas), foi realizada de forma aleatória. Portanto, em alguns casos, o número de amostras simples coletadas no sulco de plantio e utilizado na mistura foi maior do que das amostras simples col etadas externamente ao sulco, gerando maiores teores de $\mathrm{P}$ disponível nas respectivas amostras compostas formadas (Quadro 6).

Este fato pode também ser observado, quando se comparam os teores de $\mathrm{P}$ disponível obtidos nas amostras compostas com a média das amostras simpl es utilizadas na formação da amostra composta correspondente (Quadro 7), demonstrando que, em ambos os casos, as variações dos teores individuais das amostras simples influenciaram igualmente as médias, tanto que foram iguais pelo teste $t$ de Student a $5 \%$ (Quadro 7). Atribui-se a semel hança observada entre médias, em 100 \% das comparações, ao fato de que a amostra composta foi formada por amostras simples de mesmo volume (medido pela massa da subamostra), reafirmando a necessidade de coletar amostras simples de mesmo volume, ou seja, mesma seção horizontal, à mesma profundidade.

Os CV obtidos nas amostras compostas foram menores do que os obtidos nas amostras simples, tanto de trado quanto de pá de corte (Quadros 1, 3 e 5), concordando com os resultados obtidos por Santos \& Vasconcellos (1987).

Cantarutti et al. (1999) recomendam, independentemente da profundidadede amostragem, a coleta de 20 a 30 amostras simples, retiradas com trado, ou a parte central de uma fatia retirada com pá de corte (prisma com área de $4 \times 4 \mathrm{~cm}$ ), para formar uma amostra composta representativa de área homogênea sob sistema plantio convencional. Da mesma forma, recomendam, independentemente da profundidade de amostragem, a coleta de 10 a 15 fatias de solo de 3-5 cm de espessura, retiradas com pá de corte, transversalmente aos sulcos e no espaço compreendido entre os pontos médios entre sulcos, de forma que a linha de adubação fique centralizada na fatia de solo, para formar uma amostra composta representativa deárea homogênea sob sistema plantio direto. 
Quadro 6. Teores, médias, desvios-padrão e coeficientes de variação (C.V.) de fósforo disponível em amostras compostas e número das respectivas amostras simples coletadas com trado, em área há 15 anos sob sistema plantio direto

\begin{tabular}{|c|c|c|c|c|c|c|c|c|c|c|c|c|c|c|c|c|}
\hline \multirow{2}{*}{ Amostra } & \multirow{2}{*}{12 de $5^{(1)}$} & \multicolumn{3}{|c|}{$n T^{(2)}$} & \multirow{2}{*}{6 de 10} & \multicolumn{3}{|c|}{ nT } & \multirow{2}{*}{3 de 20} & \multicolumn{3}{|c|}{ nT } & \multirow{2}{*}{2 de 30} & \multicolumn{3}{|c|}{ nT } \\
\hline & & 10 & $\mathbf{s}$ & 40 & & 10 & s & 40 & & 10 & $\mathbf{s}$ & 40 & & 10 & $\mathbf{s}$ & 40 \\
\hline & $\mathrm{mg} \mathrm{dm}^{-3}$ & & & & $\mathrm{mg} \mathrm{dm}^{-3}$ & & & & $\mathrm{mg} \mathrm{dm}^{-3}$ & & & & $\mathrm{mg} \mathrm{dm}^{-3}$ & & & \\
\hline 1 & 116,4 & 2 & 2 & 1 & 92,9 & 4 & 3 & 3 & 91,3 & 5 & 9 & 6 & 54,2 & 11 & 5 & 14 \\
\hline 2 & 53,8 & 2 & 0 & 3 & 88,9 & 2 & 3 & 5 & 71,7 & 9 & 4 & 7 & 104,8 & 9 & 15 & 6 \\
\hline 3 & 72,5 & 1 & 3 & 1 & 96,1 & 1 & 5 & 4 & 64,6 & 6 & 7 & 7 & & & & \\
\hline 4 & 56,6 & 2 & 1 & 2 & 66,9 & 3 & 3 & 4 & & & & & & & & \\
\hline 5 & 76,1 & 1 & 2 & 2 & 80,5 & 7 & 2 & 1 & & & & & & & & \\
\hline 6 & 103,6 & 1 & 3 & 1 & 64,6 & 3 & 4 & 3 & & & & & & & & \\
\hline 7 & 122,8 & 2 & 3 & 0 & & & & & & & & & & & & \\
\hline 8 & 129,1 & 2 & 3 & 0 & & & & & & & & & & & & \\
\hline 9 & 51,4 & 2 & 0 & 3 & & & & & & & & & & & & \\
\hline 10 & 89,3 & 2 & 2 & 1 & & & & & & & & & & & & \\
\hline 11 & 37,4 & 1 & 0 & 4 & & & & & & & & & & & & \\
\hline 12 & 88,5 & 2 & 1 & 2 & & & & & & & & & & & & \\
\hline $\bar{Y}$ & 83,1 & & & & 81,6 & & & & 75,9 & & & & 79,5 & & & \\
\hline $\mathrm{s}$ & 30,31 & & & & 13,38 & & & & 13,83 & & & & 35,81 & & & \\
\hline C.V. (\%) & 36,47 & & & & 16,40 & & & & 18,22 & & & & 45,04 & & & \\
\hline
\end{tabular}

(1) $r$ amostras compostas formadas por $n$ amostras simples, no caso, 12 amostras compostas formadas por cinco amostras simples. (2) Número de amostras simples - nT10 (a $10 \mathrm{~cm}$ do sulco de plantio), nTs (no sulco de plantio) e nT40 (a $40 \mathrm{~cm}$ do sulco de plantio).

Quadro 7. Teores de fósforo disponível em amostras compostas de n simples, média das análises das respectivas amostras si mples $(\bar{Y}$ S) coletadas com trado e valores do testet de Student para comparar estas duas médias, em área há 15 anos sob sistema plantio direto

\begin{tabular}{|c|c|c|c|c|c|c|c|c|c|c|c|c|c|c|c|}
\hline № & 12 de $5^{(1)}$ & $\bar{Y} \mathbf{S}$ & $t^{(2)}$ & 6 de 10 & $\bar{Y} \mathbf{S}$ & $t^{(2)}$ & 3 de 20 & $\bar{Y} \mathbf{S}$ & $t^{(2)}$ & 2 de 30 & $\bar{Y} \mathbf{S}$ & $t^{(2)}$ & 1 de 60 & $\bar{Y} \mathbf{S}$ & $t^{(2)}$ \\
\hline & \multicolumn{2}{|c|}{$-\mathrm{mg} \mathrm{dm}^{-3}-$} & & \multicolumn{2}{|c|}{$-m g d m^{-3}-$} & & \multicolumn{2}{|c|}{$-m g d^{-3}-$} & & \multicolumn{2}{|c|}{$-m g d m^{-3}-$} & & \multicolumn{2}{|c|}{$-m g d m^{-3}-$} & \\
\hline 1 & 116,4 & 95,1 & $-1,786$ & 92,9 & 88,8 & $-0,193$ & 91,3 & 97,6 & 0,448 & 54,2 & 62,3 & 0,768 & 79,9 & 80,7 & 0,013 \\
\hline 2 & 53,8 & 59,1 & 0,335 & 88,9 & 82,3 & $-0,389$ & 71,7 & 70,0 & $-0,189$ & 104,8 & 99,1 & $-0,538$ & & & \\
\hline 3 & 72,5 & 75,2 & 0,152 & 96,1 & 82,9 & $-0,683$ & 64,6 & 74,4 & 0,603 & & & & & & \\
\hline 4 & 56,6 & 59,2 & 0,363 & 66,9 & 81,1 & 0,857 & & & & & & & & & \\
\hline 5 & 76,1 & 80,7 & 0,263 & 80,5 & 74,1 & $-0,247$ & & & & & & & & & \\
\hline 6 & 103,6 & 106,6 & 0,078 & 64,6 & 75,0 & 0,591 & & & & & & & & & \\
\hline 7 & 122,8 & 117,6 & $-0,135$ & & & & & & & & & & & & \\
\hline 8 & 129,1 & 127,3 & $-0,038$ & & & & & & & & & & & & \\
\hline 9 & 51,4 & 41,5 & $-1,056$ & & & & & & & & & & & & \\
\hline 10 & 89,3 & 83,5 & $-0,192$ & & & & & & & & & & & & \\
\hline 11 & 37,4 & 36,7 & $-0,131$ & & & & & & & & & & & & \\
\hline 12 & 88,5 & 85,8 & $-0,079$ & & & & & & & & & & & & \\
\hline $\bar{Y}$ & 83,1 & 80,7 & & 81,6 & 80,7 & & 75,9 & 80,7 & & 79,5 & 80,7 & & 79,9 & 80,7 & \\
\hline
\end{tabular}

(1) $\mathrm{r}$ amostras compostas formadas por $\mathrm{n}$ amostras simples, no caso, 12 amostras compostas formadas por cinco amostras simples. (2) Não-significativo a $5 \%$.

Esta recomendação demonstra que os autores consideraram, devido ao número de amostras simples preconizado, haver maior variabilidade no sistema plantio convencional, em relação ao sistema plantio direto, pois o número de amostras é diretamente proporcional aos CV das características da fertilidade do solo, dada a fórmula utilizada para cál culo (E quação 1).

Essa maior variabilidade no sistema plantio convencional pode ser conseqüência do instrumento 
utilizado para coleta de amostras. No plantio convencional, as amostras são col etadas com trado ou utiliza-se a parte central de uma pequena fatia desolo. Essas formas de amostragem, considerando o pequeno volume de solo amostrado $(\cong 0,23$ a $0,32 \mathrm{dm}^{3}$ ), tendem a apresentar maior variabilidade do que a coleta de amostras com pá de corte utilizada no sistema plantio direto $\left(\cong 4,5 \mathrm{dm}^{3}\right)$, como ficou claro pelos resultados apresentados neste estudo, comparando as duas formas de amostragem numa mesma área sob plantio direto (Quadros 1 e 3).

A amostragem nosistema de plantio convencional é, além disso, geralmente realizada depois da colheita e antes de novo preparo do solo. Ora, a manutenção de linhas de adubação é apresentada como a geradora de el evada variabilidade no sistema plantio direto (Salet et al., 1996; Anghinoni \& Salet, 1998; Schlindwein \& Anghinoni, 1998). Assim, no momento da amostragem realizada com trado, no sistema plantio convencional, a variabilidade tende a ser maior ou, no mínimo, igual à variabilidade obtida no sistema plantio direto com pá de corte, independentemente do tempo de adoção do plantio direto. Portanto, a variabilidade no sistema de plantio convencional seria menor do que no sistema plantio direto apenas se a amostragem fosse realizada após a aração e gradagem, não no momento geralmente utilizado para col eta de amostras.

Uma baixa probabilidade de erro $(\alpha=0,05$ e desvio f em relação à média de $10 \%$ ), se utilizada na equação 1, para o cál culo do número deamostras simples a serem coletadas, pode indicar o grau de confiabilidade e derepresentatividadedos resultados obtidos na amostra composta formada. Nesta condição, a col eta de pequeno número de amostras simples, tanto de pá de corte quanto de trado, é necessária para $\mathrm{pH}\left(\mathrm{H}_{2} \mathrm{O}\right), \mathrm{H}+\mathrm{Al}$ e $\mathrm{P}$-rem (Quadro 8), posto que estas características apresentaram pequena variabilidade (Quadro 1).

Por outro lado, ao utilizar $\alpha=0,05$ e desviof em relação à média de $10 \%$, para cal cular o número de amostras simples para as características da fertilidade do solo que apresentaram maior variabilidade, o númer o de amostras simples obtido foi muito superior ao recomendado por Cantarutti et al. (1999) (Quadro 9). No quadro 9, não se deve dar importância ao número de amostras simples calculado com o CV de $\mathrm{Al}^{3+}$ e de $\mathrm{Mg}^{2+}$, uma vez que estes valores foram elevados, dada a pequena magnitude da média apresentada por estas características, como já discutido anteriormente.

Schlindwein \& Anghinoni (2000) consideram a utilização de $\alpha=0,05$ e $f=10 \%$ demasiadamente exigente para as condi ções delavoura, tendo em vista os possíveis erros laboratoriais, inerentes às instal ações, equipamentos, pessoal e limitações dos próprios métodos de análise. Por isso, os mesmos autores recomendam a utilização de $\alpha=0,05$ ef $=20 \%$, valores mais compatíveis às condições de lavoura por gerarem um menor número de amostras simples por amostra composta representativa deárea homogênea.

Considerando a proposta de Schlindwein \& Anghinoni (2000), na prática, mais exeqüível, o número de amostras simples calculado para as características da fertilidade do sol oqueapresentaram maior variabilidade passa a ser compatível às condições de campo e, dentro do limiterecomendado por Cantarutti et al. (1999), quando se considera a amostragem com pá de corte (Quadro 9).

Nessa mesma condição ( $\alpha=0,05$ e $f=20 \%$ ), o número de amostras simples calculado com o CV das 60 amostras col etadas com trado continuou el evado para P disponível (Quadro 9). Dessa forma, para a coleta de 20 e 30 amostras simples com trado de caneca, considerando a variabilidade deP disponível (60 amostras) e $\alpha=0,05$, deve ser aceito um desviof em torno da média de 33,5 e 27,3\%, respectivamente.

Com base nesse resultado, é fácil compreender porque a pá de corte é utilizada como instrumento de coleta de amostras de solo no sistema plantio direto, mesmo sendo um método mais laborioso do que a col eta de amostras com trado.

Quadro 8. Número de amostras simples calculado para formar uma amostra composta, considerando a variabilidade das características pH $\left(\mathrm{H}_{2} \mathrm{O}\right), \mathrm{H}+\mathrm{Al}$ e P-rem, em área há 15 anos sob sistema plantio direto, para $\alpha=0,05$ e f $=10 \%$

\begin{tabular}{|c|c|c|c|c|}
\hline \multirow{2}{*}{ Característica } & \multicolumn{4}{|c|}{ Número de amostras simples(1) } \\
\hline & Pá de Corte & Trado(2) & Trado $(\bar{T})^{(3)}$ & Trado (MP)(4) \\
\hline $\mathrm{pH}\left(\mathrm{H}_{2} \mathrm{O}\right)$ & 1 & 1 & $1(3)$ & $1(3)$ \\
\hline $\mathrm{H}+\mathrm{Al}$ & 2 & 4 & $3(9)$ & $3(9)$ \\
\hline P-rem & 5 & 4 & $3(9)$ & $3(9)$ \\
\hline
\end{tabular}

\footnotetext{
(1) $\mathrm{n}=\left(\mathrm{t}_{\alpha / 2} \cdot \mathrm{CV} / \mathrm{f}\right)^{2}$. (2) $\mathrm{n}$ calculado com o CV das 60 amostras col etadas com trado. ${ }^{(3)} \mathrm{n}$ cal culado com o CV da média aritmética dos três locais de amostragem com trado (T10 + Ts +T40). ${ }^{(4)} \mathrm{n}$ cal culado com o CV da média ponderada dos três locais de amostragem com trado ((2T10 + Ts + 3T40)/6); () entre parêntesis o número efetivo de amostras a ser coletado, por se tratar do CV da média de três locais de amostragem.
} 
Quadro 9. Número de amostras simples calculado para formar uma amostra composta, com base na variabilidade de fósforo e potássio disponíveis, e cálcio, magnésio e alumínio trocáveis, em área há 15 anos sob sistema plantio direto, considerando $\alpha=0,05$ e $f=10$ e $20 \%$

\begin{tabular}{|c|c|c|}
\hline \multirow{3}{*}{ Característica } & \multicolumn{2}{|c|}{ № de amostras simples(1) } \\
\hline & \multicolumn{2}{|c|}{$\alpha=0,05$} \\
\hline & $f=10 \%$ & $f=20 \%$ \\
\hline $\begin{array}{l}\mathrm{P} \text { (pá de corte) } \\
\mathrm{P} \text { (trado)(2) }^{(2)} \\
\mathrm{P}(\bar{T})^{(3)} \\
\mathrm{P}(\mathrm{MP})^{(4)}\end{array}$ & $\begin{array}{r}41 \\
224 \\
45(135) \\
34(102)\end{array}$ & $\begin{array}{l}10 \\
56 \\
11(33) \\
9(27)\end{array}$ \\
\hline $\begin{array}{l}\text { K (pá de corte) } \\
\mathrm{K} \text { (trado) } \\
\mathrm{K}(\bar{T}) \\
\mathrm{K}(\mathrm{MP})\end{array}$ & $\begin{array}{l}26 \\
65 \\
27(81) \\
34(102)\end{array}$ & $\begin{array}{l}7 \\
16 \\
7(21) \\
9(27)\end{array}$ \\
\hline $\begin{array}{l}\mathrm{Ca}^{2+} \text { (pá de corte) } \\
\mathrm{Ca}^{2+} \text { (trado) } \\
\mathrm{Ca}^{2+}(\bar{T}) \\
\mathrm{Ca}^{2+}(\mathrm{MP})\end{array}$ & $\begin{array}{l}30 \\
57 \\
27(81) \\
25(75)\end{array}$ & $\begin{array}{l}8 \\
14 \\
7(21) \\
6(18)\end{array}$ \\
\hline $\begin{array}{l}\mathrm{Mg}^{2+} \text { (pá de corte) } \\
\mathrm{Mg}^{2+} \text { (trado) } \\
\mathrm{Mg}^{2+}(\bar{T}) \\
\mathrm{Mg}^{2+}(\mathrm{MP})\end{array}$ & $\begin{array}{l}32 \\
70 \\
62(186) \\
63(189)\end{array}$ & $\begin{array}{l}8 \\
17 \\
15(45) \\
16(48)\end{array}$ \\
\hline $\begin{array}{l}\mathrm{Al}^{3+} \text { (pá de corte) } \\
\mathrm{Al}^{3+} \text { (trado) } \\
\mathrm{Al}^{3+}(\bar{T}) \\
\mathrm{Al}^{3+}(\mathrm{MP})\end{array}$ & $\begin{array}{l}73 \\
124 \\
92(276) \\
87(261)\end{array}$ & $\begin{array}{l}18 \\
31 \\
23(69) \\
22(66)\end{array}$ \\
\hline
\end{tabular}

(1) $\mathrm{n}=\left(\mathrm{t}_{\alpha / 2} \mathrm{CV} / \mathrm{f}\right)^{2}$. $^{(2)} \mathrm{n}$ calculado com o CV das 60 amostras col etadas com trado. ${ }^{(3)} \mathrm{n}$ calculado com o CV da média aritmética dos três locais de amostragem com trado (T10 + Ts + T40). (4) $\mathrm{n}$ calculado com o CV da média ponderada dos três locais de amostragem com trado ((2T10 +Ts +3T40)/6); () entre parêntesis o número efetivo de amostras a ser col etado, por se tratar do CV da média de três locais de amostragem.
Por outro lado, o número de amostras simples calculado ( $\alpha=0,05$ ef $=20 \%$ ) com o CV da média ponderada (MP) dos três locais de amostragem com trado foi inferior, para P disponível, ao calculado com o CV da média aritmética $(\bar{T})$ e ao cal culado com o CV das 60 amostras simples coletadas com trado (Quadro 9), sendo um número muito mais coerente às práticas de campo.

A média ponderada dos três locais de amostragem com trado, utilizada neste estudo, pode ser extrapolada para o campo, fazendo-se a coleta localizada de $17 \%$ das amostras no sulco de plantio, $33 \%$ a $10 \mathrm{~cm}$ do sulco e $50 \%$ no ponto médio entre sulcos.

Para validar esse tipo de amostragem local izada, foram realizadas simulações de amostragem, gerando-se 15 amostras compostas, formadas, cada uma, por cinco amostras (17\%) escolhidas al eatoriamente no grupo de 20 amostras coletadas com trado no sulco de plantio, nove (33\%) amostras no grupo de 20 amostras col etadas a $10 \mathrm{~cm}$ do sulco e 13 (50\%) amostras no grupo de 20 amostras col etadas no ponto médio entre sulcos, do total de 27 amostras simples preconizado para P disponível, utilizando-se a média ponderada (MP) (Quadro 9).

Para todas as características de fertilidade estudadas, as médias das 15 amostras compostas (simulações) foram muito semel hantes aos valores obtidos, quando foi estimada a média ponderada (MP) dos três locais de amostragem com trado (Quadros 1, 3 e 10). Além disso, o maior desvio f em relação à média das 15 amostras compostas simuladas foi de $13 \%$ para P disponível (Quadro 10). Esses resultados validam a coleta localizada de amostras de solo com trado de caneca, para o sistema plantio direto, dentro da probabilidade de erro $(\alpha=$ 0,05 e $f=20 \%$ ) sugerida por Schlindwein \& Anghinoni (2000).

Quadro 10. Médias, desvios-padrão, coeficientes de variação, diferenças entre as maiores e menores observações $(Y>-Y<$ ), limites superior (Ls) e inferior ( $\mathrm{Li}$ ) de características da fertilidade do solo e desvios em relação à média (f \%), obtidos em 15 amostras compostas simuladas, utilizando-se a média ponderada ((2T10 + Ts + 3T40)/6), em área há 15 anos sob sistema plantio direto

\begin{tabular}{|c|c|c|c|c|c|c|c|}
\hline Característica & $\bar{Y}$ & $\mathbf{s}$ & C.V. & $Y>-Y<(1)$ & $\mathbf{L} \mathbf{s}^{(2)}$ & Li & $f(3)$ \\
\hline & & & $\%$ & & & & $\%$ \\
\hline $\begin{array}{l}\mathrm{pH} \\
\mathrm{P}\left(\mathrm{mg} \mathrm{dm}^{-3}\right) \\
\mathrm{K}\left(\mathrm{mg} \mathrm{dm}^{-3}\right) \\
\mathrm{Al} \mathrm{I}^{3+}\left(\mathrm{cmol}_{\mathrm{c}} \mathrm{dm}^{-3}\right) \\
\mathrm{Ca}^{2+}\left(\mathrm{cmol}_{c} \mathrm{dm}^{-3}\right) \\
\mathrm{Mg} \mathrm{g}^{2+}\left(\mathrm{cmol}_{\mathrm{c}} \mathrm{dm}^{-3}\right) \\
\mathrm{H}+\mathrm{Al}\left(\mathrm{cmol}_{\mathrm{c}} \mathrm{dm}^{-3}\right) \\
\text { P-rem }\left(\mathrm{mg} \mathrm{L}^{-1}\right)\end{array}$ & $\begin{array}{r}5,14 \\
65,20 \\
90,50 \\
0,27 \\
2,29 \\
0,37 \\
5,88 \\
32,59\end{array}$ & $\begin{array}{l}0,033 \\
5,702 \\
4,725 \\
0,021 \\
0,092 \\
0,018 \\
0,090 \\
0,441\end{array}$ & $\begin{array}{l}0,65 \\
8,75 \\
5,22 \\
8,02 \\
4,00 \\
5,05 \\
1,54 \\
1,35\end{array}$ & $\begin{array}{r}0,10 \\
17,63 \\
17,07 \\
0,08 \\
0,33 \\
0,06 \\
0,32 \\
1,20\end{array}$ & $\begin{array}{r}5,19 \\
73,80 \\
97,71 \\
0,30 \\
2,43 \\
0,39 \\
6,02 \\
33,26\end{array}$ & $\begin{array}{r}5,09 \\
56,50 \\
83,38 \\
0,24 \\
2,15 \\
0,34 \\
5,74 \\
31,92\end{array}$ & $\begin{array}{r}1 \\
13 \\
8 \\
11 \\
6 \\
7 \\
2 \\
2\end{array}$ \\
\hline
\end{tabular}

(1) Maiores e menores teores das 15 amostras compostas simuladas. ${ }^{(2)}$ Calculados segundo método de comparação da FAO (Ls $=\overline{\mathrm{y}}$ $\left.+t_{0,05 / 2} \times s / \sqrt{2} ; L i=\bar{y}-t_{0,05 / 2} \times s / \sqrt{2}\right) \cdot{ }^{(3)} f=100((L s-\bar{y}) / \bar{y})=100((\bar{y}-L i) / \bar{y})$. 
Assim, pode-se recomendar a coleta, com trado de caneca, de cinco amostras no sulco de plantio, nove amostras a $10 \mathrm{~cm}$ do sulco e 13 amostras no ponto médio entre sulcos, para o sistema plantio direto. Sugere-se, também, essa forma deamostragem para o plantio convencional, caso a coleta de amostras seja realizada depois da colheita e antes de novo preparo do solo.

Dessa forma, deve-se considerar o trabalho necessário para col etar dez amostras com pá decorte ou 27 amostras com trado, pois, uma vez queambos os métodos caracterizam corretamente a fertilidade média da área amostrada, não se justifica maior esforço de amostragem tampouco maior tempo de execução.

\section{CONCLUSÕES}

1. Os teores de $\mathrm{K}$ disponível, $\mathrm{Mg}^{2+}$ trocável e os val ores de $\mathrm{H}+\mathrm{Al}$ foram os únicos que diferiram ao se proceder à amostragem com pá de corte ou com trado de caneca.

2. Na amostragem com trado de caneca, a variabilidade de todas as características avaliadas e o número cal culado de amostras simples necessário à formação de uma amostra composta foram maiores do que na amostragem com pá de corte; todavia, a amostragem localizada com trado (17\% das amostras no sulco de plantio, $33 \%$ a $10 \mathrm{~cm}$ do sulco e $50 \%$ no ponto médio entre sulcos) ea amostragem com pá de corte proporcionaram variabilidades muito semel hantes.

3. A variabilidade foi baixa para $\mathrm{P}$-rem, $\mathrm{H}+\mathrm{Al}$ e $\mathrm{pH}\left(\mathrm{H}_{2} \mathrm{O}\right)$ e alta para $\mathrm{P}, \mathrm{Al}^{3+}, \mathrm{Mg}^{2+}, \mathrm{K}$ e Ca ${ }^{2+}$.

4. Pequeno número de amostras simples, utilizando-se a pá de corte ou o trado de caneca, foi necessário para formar uma amostra composta, dentro dos limites que conferem maior exatidão ( $\alpha$ $=0,05$ e $\mathrm{f}=10 \%)$, para $\mathrm{pH}\left(\mathrm{H}_{2} \mathrm{O}\right), \mathrm{H}+\mathrm{Al}$ e P-rem; Porém, para $\mathrm{P}$ disponível, o número de amostras simples foi muito el evado nesta condição.

5. Considerando limites menos exigentes $(\alpha=$ 0,05 ef $=20 \%$ ), 10 amostras simples col etadas com pá de corte ou 27 amostras simples coletadas de forma localizada com trado de caneca (cinco amostras coletadas no sulco de plantio, nove coletadas a $10 \mathrm{~cm}$ do sulco e 13 col etadas no ponto médio entre sulcos) foram necessárias à formação de uma amostra composta representativa da área há 15 anos sob sistema plantio direto.

6. As análises das amostras compostas, tanto de pá de corte quanto de trado, apresentaram valores semel hantes às médias das anál ises das respectivas amostras simples, caracterizando corretamente a fertilidade média da unidade de amostragem.

\section{LITERATURA CITADA}

ALVAREZ V., V.H. \& CARRARO, I.M. Variabilidade do solo numa unidade de amostragem em solos de Cascavel e de Ponta Grossa, Paraná. R. Ceres, 23:503-510, 1976.

ALVAREZ V., V.H.; CAJ USTE, L.J . \& CRUZ DIAZ, J . Estudio de la variabilidad en el contenido de fósforo del suelo en función de las dosis y ubicación del fertilizante fosfatado en un experimento de maiz (Zea mays L.). Agrociencia, 64:23-32, 1986.

ALVAREZ V., V.H.; NOVAIS, R.F.; DIAS, L.E. \& OLIVEIRA, J .A. Determinação e uso do fósforo remanescente, B. Inf., SBCS, 52:27-32, 2000.

ALVES, J.F.O. Amostragem e análise da variabilidade de algumas características químicas e físicas de quatro solos de Minas Gerais. Viçosa, Universidade Federal de Viçosa, 1996. 64p. (Tese de Mestrado)

ANGHINONI, I. \& SALET, R.L. Amostragem do solo e as recomendações de adubação e calagem no sistema plantio direto. In: NUERNBERG, N.J., ed. Conceitos e fundamentos do sistema plantio direto. Lages, Sociedade Brasileira de Ciência do Solo, 1998. p.27-52.

BARRETO, A.C.; NOVAIS, R.F. \& BRAGA, J .M. Determinação estatística do número de amostras simples de solo por área para avaliação da sua fertilidade. R. Ceres, 21:142-147, 1974.

CANTARUTTI, R.B.; ALVAREZ V., V.H. \& RIBEIRO, A.C. Amostragem do solo. In: RIBEIRO, A.C.; GUIMARÃES, P.T.G.; ALVAREZV., V.H., eds. Recomendações para o uso de corretivos e fertilizantes em Minas Gerais (5a Aproximação). Viçosa, MG, 1999. p.13-20.

JACKSON, M.L. Soil chemical analysis. Englewood Cliffs, Prentice Hall, 1970. 489p.

SALET, R.L.; KRAY, C.H.; FORNARI, T.G.; CONTE, E.; KOCHHANN, R.A. \& ANGHINONI, I. Variabilidade horizontal e amostragem de solo no sistema plantio direto. In: REUNIÃO SUL-BRASI LEIRA DE CIÊNCIA DO SOLO, 1., Lages, 1996. Resumos Expandidos. Lages, Sociedade Brasileira de Ciência do Solo, 1996. p.74-76.

SANTOS, H.L. \& VASCONCELOS, C.A. Determinação do número de amostras de solo para análise química em diferentes condições de manejo. R. Bras. Ci. Solo, 11:97100, 1987.

SARAIVA, O.F.; ALVAREZ V., V.H. \& COSTA, L.M. Variabilidade dealgumas características físicas equímicas de um Podzólico Vermel ho-Amarelo Câmbico distrófico. R. Ceres, 39:529-541, 1992.

SCHLINDWEIN, J.A. \& ANGHINONI, I. Variabilidade dos índices de fertilidade do solo no sistema plantio direto e coletas de amostras representativas. In: REUNIÃO SULBRASILEIRA DE CIÊNCIA DO SOLO, 2., Santa Maria, 1998. Resumos Expandidos. Santa Maria, Sociedade Brasileira de Ciência do Solo, 1998. p.142-145.

SCHLINDWEIN, J.A. \& ANGHINONI, I. Variabilidade horizontal de atributos de fertilidade e amostragem do solo no sistema plantio direto. R. Bras. Ci. Solo, 24:85-91, 2000. 
SCHLINDWEIN, J.A.; SALET, R.L. \& ANGHINONI, I. Variabilidade dos índices de fertilidade do solo no sistema plantio direto e col etas de amostras representativas do solo. In: REUNIÃO BRASILEIRA DE FERTILIDADE DO SOLO E NUTRIÇÃO DE PLANTAS, 23.; REUNIÃO BRASILEIRA SOBRE MICORRIZAS, 7.; SIMPÓSIO BRASILEIRO SOBRE MICROBIOLOGIA DO SOLO, 5; REUNIÃO BRASILEIRA DE BIOLOGIA DO SOLO, 2 ., Caxambú, 1998. Resumos. Caxambú, Sociedade Brasileira de Ciência do Solo, 1998. p.265. van den HENDE, A. \& COTTENIE, A. L'estimation dela fertilité du sol par les méthodes chimiques nouvelles. In: Comp. Rend. des Recherches; Travaux du Centre de Chemie Physique Agricole. Bruxelles. IRSIA, 25:27:174, 1960. 